\title{
Graft copolymerization of acrylonitrile onto Saccharum cilliari fiber
}

\author{
A.S. Singha, Anjali Shama, Vijay Kumar Thakur ${ }^{*}$ \\ *Applied Chemistry Research Laboratory, National Institute of Technology Hamirpur- \\ 177005, Himachal Pradesh- India; tel: +91-1972 -254120; fax: +91-1972 -223834; e- \\ mail: assingha@gmail.com, vijaythakurnit@gmail.com
}

(Received: 6 July, 2008; published: 11 September, 2009)

\begin{abstract}
The present paper deals with the graft copolymerization of acrylonitrile (AN) onto Saccharum cilliare fiber in air in the presence of ferrous ammonium sulfate potassium persulphate (FAS - KPS) as redox initiator. Various reaction parameters such as solvent, time, temperature, $\mathrm{pH}$ and concentration of monomer and initiator were optimized in order to get maximum graft yield (69\%). Raw fiber and its graft copolymers with AN were then subjected for evaluation of different properties. Characterization of the graft copolymers was carried out with Scanning electron microscope, Fourier transform infrared spectrophotometer and X-ray diffraction studies (X-RD).

Key Words: Saccharum cilliare, graft copolymers, acrylonitrile, ferrous ammonium sulphate - potassium persulphate, swelling behavior.
\end{abstract}

\section{Introduction}

Development of innovative polymer materials from lignocellulosic fibers has increased significantly during the last few years because of their advantages over synthetic fibers [1-5]. The advantages of such fibers over traditional synthetic fibers such as glass fibers are: low density, relatively high toughness, high strength and stiffness, good thermal properties and biodegradability etc. [6-11]. Although natural fibers have various advantages they have got inherited disadvantages like moisture sensitivity, poor chemical resistance etc which hamper their use in many applications. However these properties can be improved by many methods like grafting, acetylation, silane treatment etc [12-17]. Among these methods grafting is one of the most exercised method for improving the existing properties of the natural cellulosic fibers [18-22]. It imparts the additional and desired properties to the fiber without affecting its basic properties. The formation of graft copolymer with sufficiently long polymeric sequences of diverse chemical composition opens the way to afford specialty polymeric materials. It has been found that incorporation of nitrogen, phosphorous or halogen containing organic and inorganic compounds provides thermal stability to the polymer backbone. Various researchers have worked on the thermal stability and other properties of graft copolymers [23-24]. The grafting process depends on the reactivity of monomers used, the type of initiation and cellulose accessibility etc [25-27]. A graft copolymer results from chemical interaction of a growing polymer chain with different polymeric substrate [28- 
32]. Dimensional stability, resistance to abrasion and wear, wrinkle recovery, oil and water repellency, heat resistance, and antimicrobial activity are other examples of properties that can be improved by graft-copolymerization of cellulose. Graft copolymerization of vinyl monomers onto polymeric materials, including cellulose and cellulose derivatives, has been the subject of extensive studies [33-37]. In general two major types of grafting techniques considered for modifying the properties of lignocellulosic natural fibers are: (i) grafting with a single monomer and (ii) grafting with a mixture of two (or more) monomers. The first type of polymerization reaction usually occurs in a single step, but the second may occur with either the simultaneous or sequential use of the two monomers. Mosaic grafting has attracted much attention for binary monomer grafting. Two different monomers are grafted side-by-side to obtain the requisite property.

A lot of research work has been done on techniques of graft co-polymerization of different monomers on polymeric backbones. These techniques include chemical, radiation, photochemical, plasma-induced techniques and enzymatic grafting. The chemical grafting can proceed along two major paths, viz. free radical and ionic. In the chemical process, the role of initiator is very important as it determines the path of the grafting process. Apart from the general free-radical mechanism, grafting in the melt and atom transfer radical polymerization (ATRP) are also interesting techniques to carry out grafting.

During free-radical grafting, in the chemical process, free radicals are produced from the initiators and transferred to the substrate to react with monomer to form the graft copolymers [22]. In general, one can consider the generation of free radicals by indirect or direct methods. One of the most suitable examples of free radicals produced by an indirect method is the production through redox reaction, viz. $\mathrm{M}^{\mathrm{n}+} / \mathrm{H}_{2} \mathrm{O}_{2}$, persulphate.

Free-radical sites may be generated on a polymeric backbone by direct oxidation of the backbone by certain transition metal ions. The redox potential of the metal ions is the important parameter in determining the grafting efficiency. In general, metal ions with low oxidation potential are preferred for better grafting efficiency. The proposed mechanism for such a process has been ascribed to the intermediate formation of a metal ion- polymer chelate complex; viz. ceric ion is known to form a complex with hydroxyl groups on a polymeric backbone, which can dissociate via one electron transfer to give free radicals [29-30]

Grafting can also proceed through an ionic mode. Most useful initiators for carrying out graft copolymerization reactions are alkali metal suspensions in a Lewis base liquid, organ metallic compounds and sodium naphthalenide etc. Alkyl aluminum $\left(R_{3} A l\right)$ and the backbone polymer in the halide form (ACl) interact to form carbonium ions along the polymer chain, which leads to copolymerization. The reaction proceeds through cationic mechanism. Grafting can also proceed through an anionic mechanism. Sodiumammonia or the methoxide of alkali metals form the alkoxide of polymer $\left(\mathrm{PO}^{-} \mathrm{Na}^{+}\right)$, which reacts with monomer to form the graft co-polymer [22].

Among various types of biofibrous material, Saccaharum cilliare fibers which are abundantly found in the Himalayan region have got high potential as a renewable fabric in various applications especially in polymer composites. Traditionally this fibrous 
material is being used by the local people for making low cost articles like socks, boots, mats, ropes, bags etc. The literature survey has revealed that not many studies have been made on the applications of this precious wealth of the nature. The work reported in the present research paper is a part of comprehensive research work initiated in our laboratory to effectively use eco-friendly biofibers in a number of applications. The objective of the present investigation has been to improve/modify the existing properties of $S$. cilliare fiber through graft copolymerization of acrylonitrile onto it and to study their physical and chemical properties.

\section{Results and Discussion}

It has been observed that polymeric materials containing cellulose, $\mathrm{C}_{2}, \mathrm{C}_{3}$ and $\mathrm{C}_{6}-\mathrm{OH}$ groups and $\mathrm{C}-\mathrm{H}$ sites are the active centers for grafting of polymeric chains onto polymeric backbone. Potassium persulphate takes part in the redox reaction with $\mathrm{Fe}^{2+}$ as given below:

$\mathrm{Fe}^{2+}+\mathrm{O}_{3} \mathrm{~S}^{-} \mathrm{O}-\mathrm{O}-\mathrm{SO}_{3-} \longrightarrow \mathrm{Fe}^{3+}+\mathrm{SO}_{4}{ }^{2-}+\mathrm{SO}_{4}{ }^{-*}$

Interaction of $\mathrm{SO}_{4}^{-{ }^{-*}}$ with $\mathrm{H}_{2} \mathrm{O}$ generates $\mathrm{OH}$ free radicals which are responsible for graft copolymerization onto S.Cilliare fiber.

Optimization of different reaction parameters for grafting of acrylonitrile onto S. cilliare fiber

Optimization of various reaction parameters like amount of the solvent, reaction time, temperature, $\mathrm{pH}$, ratio of the initiator (FAS-KPS ratio) and concentration of the monomer was carried out for graft co-polymerization of acrylonitrile onto S. cilliare fiber. It has been experimentally found that the optimum conditions for maximum graft yield $(69.0 \%)$ were: solvent-150 ml; time-120 min; temperature- $35{ }^{\circ} \mathrm{C}$; $\mathrm{pH}-4.0$; FAS: KPS-1:1 and monomer- $(15.83 \times 10-3 \mathrm{~mol} / \mathrm{L})$ as given in Table- 1 .

\section{Grafting Kinetics}

It has been discovered that grafting increases with increase in monomer concentration and after reaching the maximum grafting of $69 \%$ further increase in acrylonitrile concentration results in decrease of graft yield as shown in (Table1). This probably happens due to the high proportion of homopolymerization over graft copolymerization at higher monomer concentration.

Present study reveals that solvent, time and temperature also have a significant effect on the grafting. With the increase in amount of solvent reaction time and temperature grafting was found to increase (Table1). The maximum grafting took place when $150 \mathrm{ml}$ solvent was used. Further increase in solvent resulted in decreased graft yield. This probably occurs due to the dilution of reaction medium which lower the concentration of monomer radical per unit volume and hence less grafting takes place.

The optimum reaction temperature and time has been found to be $35{ }^{\circ} \mathrm{C}$ and $120 \mathrm{~min}$ respectively. With further increase in temperature and time a decrease in grafting has been observed. This may be due to the competition of various side chain reactions like hydrogen abstraction reactions along with excessive homo-polymerization at elevated temperature and time. 
Tab. 1. Optimization of various reaction parameters for maximum graft co-polymerization of acrylonitrile onto S. cilliare fiber.

\begin{tabular}{|c|c|c|c|c|c|c|c|c|}
\hline $\begin{array}{l}\text { Sr. } \\
\text { No. }\end{array}$ & $\begin{array}{l}\text { Solvent } \\
(\mathrm{ml})\end{array}$ & $\begin{array}{l}\text { Monomer } \\
\mathrm{mol}_{3}\end{array}$ & $\begin{array}{l}\text { FAS- } \\
\text { KPS } \\
\text { ratio }\end{array}$ & Time(min) & $\underset{{ }^{0} \mathrm{C}}{\text { Temp. }}$ & $\mathrm{pH}$ & $\begin{array}{l}\% \\
\text { grafting }\end{array}$ & $\begin{array}{l}\% \\
\text { efficiency }\end{array}$ \\
\hline 1. & 100 & 6.78 & $1: 1$ & 120 & $35^{\circ} \mathrm{C}$ & 2.0 & 14.0 & 3.50 \\
\hline 2. & 125 & ," & , &, & ", &, & 17.6 & 4.4 \\
\hline 3. & 150 & , & " & , & , & ", & 19.3 & 4.82 \\
\hline 4. & 175 &, &, &, & ," & ," & 16.5 & 4.12 \\
\hline 5. & 200 &, & ," &, &, & , & 6.0 & 1.50 \\
\hline 6. & 150 & ," & ", & 30 & ," & ", & 11.8 & 2.95 \\
\hline 7. & ," & ," & , & 60 & , & , & 13.3 & 3.32 \\
\hline 8. & ," & , & , & 90 & ," & ," & 13.6 & 3.34 \\
\hline 9. & ," & ," & , & 150 & , & , & 15.0 & 3.75 \\
\hline 10. & ," & ," & ," & 180 & 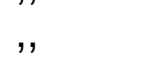 & ", & 12.0 & 3.00 \\
\hline 11. & , & , & , & 120 & 25 & , & 4.8 & 1.20 \\
\hline 12. & ," & , & , &, & 45 & ", & 15.4 & 3.85 \\
\hline 13. & ," & ," & ," &, & 55 & ," & 13.7 & 3.42 \\
\hline 14. &,, &, &, &, & 65 &, & 10.5 & 2.62 \\
\hline 15. & ," & ," &, &, & 75 & ," & 7.2 & 1.8 \\
\hline 16. & ," & ," & $0.125: 1$ &, & 35 & , & 7.7 & 1.92 \\
\hline 17. &, &, & $0.250: 1$ &, &, &, & 11.0 & 2.75 \\
\hline 18. &, &, & $0.5: 1$ &, &, &, & 17.8 & 4.45 \\
\hline 19. & ", & ," & $1.250: 1$ & ," & ," & ", & 13.3 & 3.32 \\
\hline 20. & ", &, & $1.50: 1$ & , &, & & 1.5 & 0.37 \\
\hline 21. & ," & , & $1: 1$ & , & , & 2.0 & 19.3 & 4.82 \\
\hline 22. & , & , & " & , & " & 4.0 & 25.5 & 6.37 \\
\hline 23. & ," & ," & ", & ," & ," & 6.0 & 15.8 & 3.95 \\
\hline 24. & ," & ," & ," & ," & ," & 8.0 & 8.3 & 2.07 \\
\hline 25. &,, & &, &, &, & 10 & 4.0 & 1.00 \\
\hline 26. & , & 4.52 &, &, & ," & 4.0 & 7.4 & 2.77 \\
\hline 27. &, & 6.78 &, &, &, &, & 25.5 & 6.37 \\
\hline 28. &, & 9.03 &, &, &, &, & 27.3 & 5.12 \\
\hline 29. &, & 11.30 &, &, &, & , & 28.8 & 4.32 \\
\hline 30. &, & 13.55 & , &, & ,, &, & 66.0 & 8.25 \\
\hline 31. & , & 15.83 & , & , & , & , & 69.0 & 7.39 \\
\hline 32. &, & 18.08 &, & ," & ," &, & 45.0 & 4.22 \\
\hline
\end{tabular}

The molar ratio of initiator (FAS-KPS) plays a significant role in order to get maximum graft yield (Table1). The optimum molar ratio for the maximum graft yield was found to be $1: 1$. It has been observed that with the further increase in molar ratio, the grafting was found to decrease. This may be due to the fact that at higher molar ratio more $\mathrm{Fe}$ ${ }^{3+}$ ions are generated which result in the termination of growing chains. If FAS-KPS molar ratio is lower than the critical value, then there is decrease in grafting because of lesser generation of $\mathrm{OH}$ free radicals. 
It has also been observed that the rate of grafting depend upon the $\mathrm{pH}$ value of the reaction medium. With the increase in $\mathrm{pH}$ of reaction medium, grafting process increases up to a $\mathrm{pH}$ value of 4.0 .

Physico-Chemical studies on raw fiber and its graft copolymer

Grafted and ungrafted fibers thus prepared were subjected for the evaluation of physical and chemical properties such as swelling behavior, moisture absorbance behavior, water uptake, chemical resistance etc.

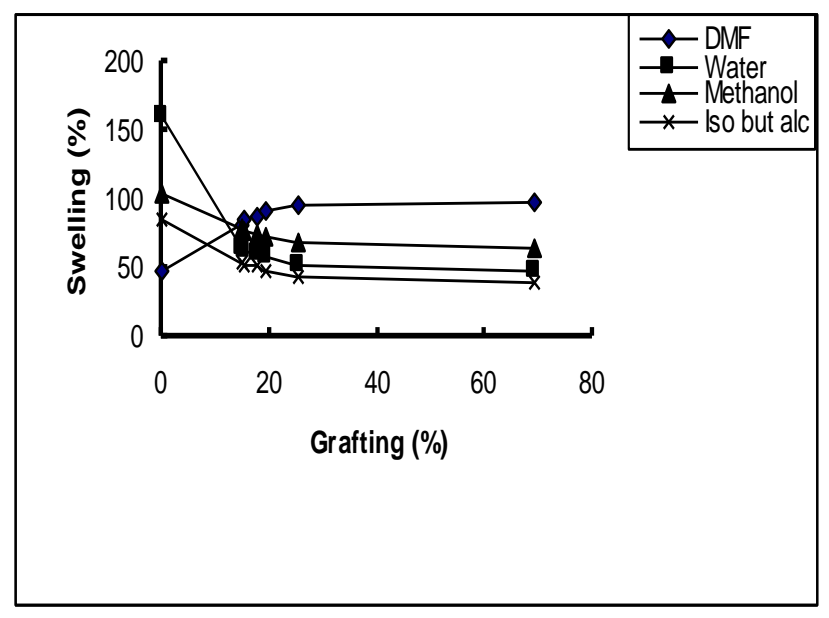

Fig.1. Swelling behavior of grafted fiber in different solvents.

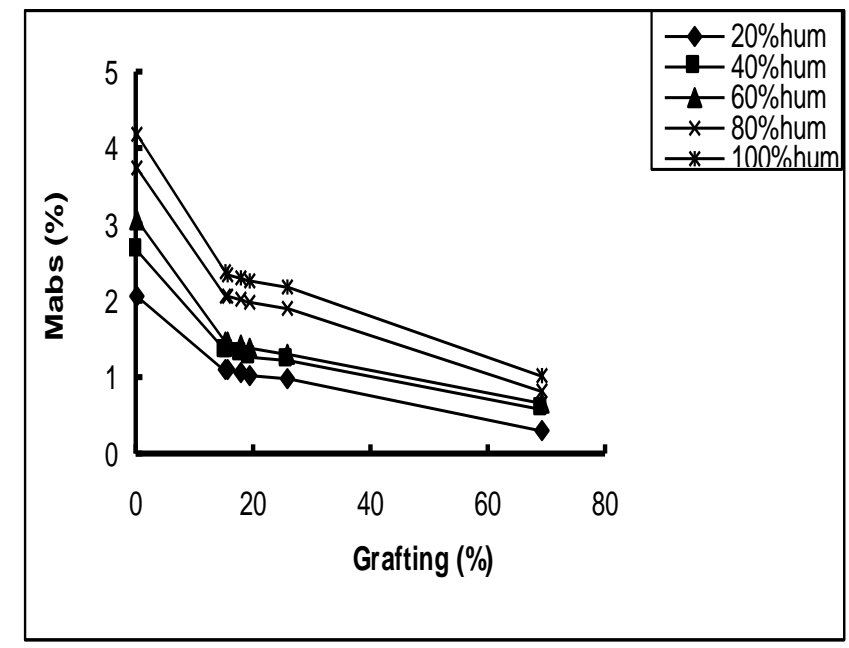

Fig. 2. Moisture absorbance under different humidity levels.

Raw and grafted fibers show different swelling behavior in different solvents (Fig. 1). The swelling behavior of ungrafted fiber in different solvents follows the trend: water > methanol > isobutyl alcohol > dimethylformamide. Whereas in grafted fiber, it varies as a function of grafting and follow the trend: dimethylformamide $>$ methanol $>$ water $>$ isobutyl alcohol. This trend in ungrafted fibers may be due to greater affinity of water for 
$\mathrm{OH}$ groups present in the raw S. cilliare fiber which result in more dispersion of water into the polymeric backbone as compared to other solvents. While in case of grafted fibers containing acrylonitrile monomer chains, water and alcohols cannot interact with the grafted fiber to the extent as they do with raw fiber. This may be due to blockage of active sites on polymeric substrate by poly(acrylonitrile) chain which causes change in the sorption behaviour of the different solvents. Since poly(acrylonitrile) chains on grafted fiber are more solvolysed by dipolar aprotic solvent dimethylformamide as compared to water or alcohol, so more swelling took place in dimethylformamide as compared to other solvents.

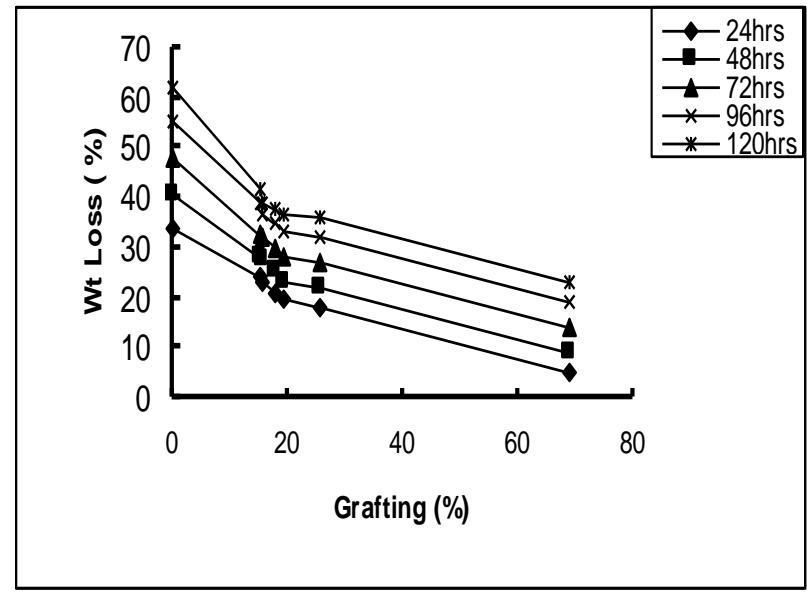

Fig. 3.Effect of grafting on chemical resistance against $1 \mathrm{~N} \mathrm{HCl}$.

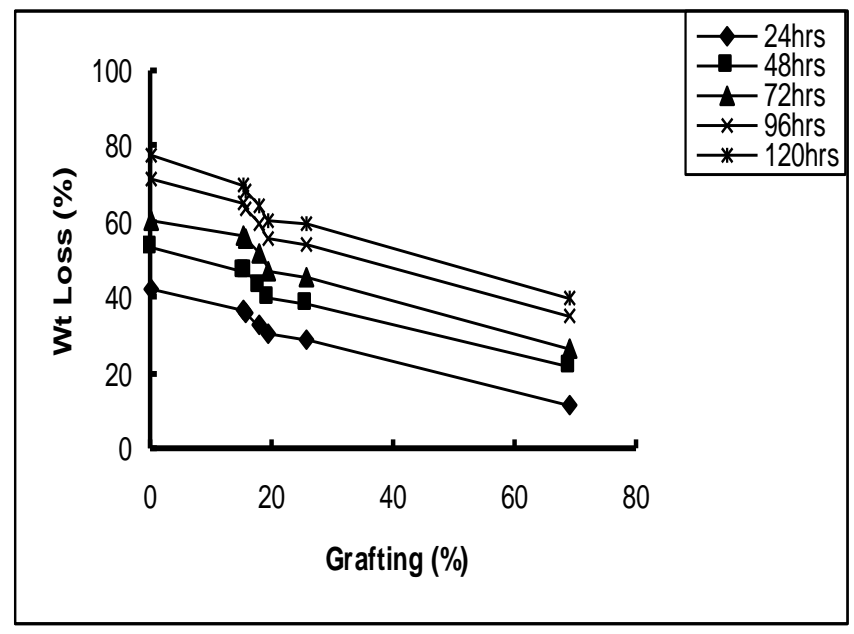

Fig. 4. Effect of grafting on chemical resistance against $1 \mathrm{~N} \mathrm{NaOH}$.

The moisture absorbance behavior at different humidity levels as a function of grafting has been depicted in the (Fig 2). It has been found that moisture absorbance (Mabs) decreases with the increase in grafting. The raw fiber shows more moisture absorbance than the grafted fibers. This behavior of grafted fibers may be due to the fact that with 
the increase in grafting the active sites for maximum moisture absorbance were replaced by the polyacrylonitrile chains grafted onto the fiber. Since polyacrylonitrile chains have lesser affinity towards water as compared to the original raw S. cilliare fiber, so Mabs decreases with the increase in grafting.

Further it has been observed that in comparison to raw fiber grafted fiber show more resistance towards chemicals (Fig $3 \& 4$ ). This is understandable as the active sites of raw fiber get blocked by grafted polyacrylonitrile chains and thereby resulting in resistance towards the chemicals.

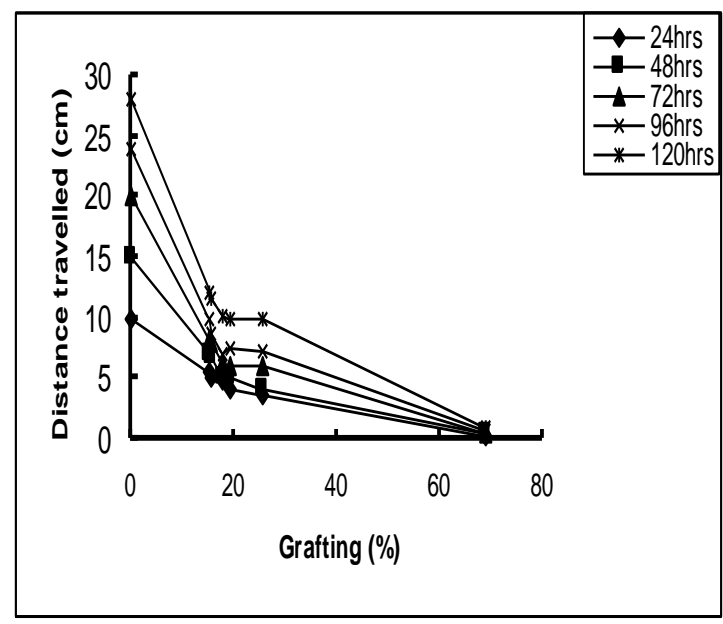

Fig. 5. Effect of grafting on water uptake behavior at different time intervals.

Water up take capacity of graft copolymers was found to decrease with increase in grafting (Fig. 5). This could be explained on the basis of the explanation already given above.

\section{Conclusions}

It has been found that graft copolymerization through acrylonitrile helps in improving the properties of Saccharum cilliare fiber. The properties like moisture absorbance, chemical resistance, swelling behaviour and water uptake varies directly with the grafting. With the increase in grafting the above properties (except chemical resistance which increases) have been found to decrease. X-Ray diffraction studies have revealed that the crystallinity of fiber decreases with the increase in the grafting. This clearly indicates that grafting is a best way to improve the properties of raw fiber.

\section{Experimental Part}

\section{Purification of Material}

Natural fiber Saccharum cilliare was treated with $5 \%$ sodium bisulphate under pressure for 3-4 h' to remove lignin contents. Then the fiber was dried in a hot air oven at $50{ }^{\circ} \mathrm{C}$ to a constant weight. Purification of acrylonitrile was done by firstly washing with $5 \%$ sodium hydroxide and then drying over anhydrous $\mathrm{Na}_{2} \mathrm{SO}_{4}$ followed by distillation. 
Potassium persulphate (KPS) was used as received and ferrous ammonium sulphate (FAS) was recrystallized from hot water.

\section{Methods}

\section{-Graft copolymerization}

The Saccharum cilliare fiber $(0.5 \mathrm{~g})$ was masticated and then immersed in a known amount of distilled water for $24 \mathrm{~h}$. A known amount of initiator (FAS- KPS) and monomer (AN) was then added into the flask containing fiber. The reaction mixture was stirred at fixed $\mathrm{pH}$ and temperature for $120 \mathrm{~min}$. Optimum conditions of solvent, time, temperature, initiator (FAS-KPS ratio), $\mathrm{pH}$ and monomer concentration were determined so as to get maximum graft yield (Table 1). The homo-polymer formed during graft copolymerization was removed from graft copolymers by extraction with dimethylformamide in a Soxhlet extraction apparatus for $48 \mathrm{~h}$. The graft copolymer was then dried in hot air oven to a constant weight. The percentage of grafting $(\mathrm{Pg})$ and efficiency $(\mathrm{Pe})$ were calculated as per procedure reported earlier [28-30].

$$
\begin{aligned}
& \left(P_{g}\right)=\frac{W_{g}-W_{r}}{W_{r}} \times 100 \\
& \left(P_{e}\right)=\frac{W_{g}-W_{r}}{W_{m}} \times 100
\end{aligned}
$$

where $W_{g}, W_{r}$ and $W_{m}$ are weights of grafted fiber, raw fiber and monomer respectively.

\section{Physico-chemical studies}

Since surface modification of natural fibres affects the crystalline regions of cellulosic materials, so it affects many physical and chemical properties of fibres such as swelling, thermal behaviour, moisture absorbance, water uptake, and chemical resistance etc. Grafted/ungrafted Saccaharum ciliare fibres thus prepared were subjected for the evalution of physical and chemical properties such as swelling behavior, moisture absorbance behavior, water uptake and chemical resistance etc.

Swelling behavior of the grafted and ungrafted samples of Saccaharum ciliare fibres was determined by treating with dimethylformamide, water, methanol and isobutyl alcohol. Known initial weight $W_{i}$ of the grafted samples and raw sample were immersed in 100 $\mathrm{ml}$ of solvents at room temperature for $24 \mathrm{~h}$ [22]. The samples were then filtered and the excess solvent was removed with the help of filter paper and then final weight $W_{f}$ was noted on Libror AEG-220, Shimadzu make electronic balance.

The percent swelling was then calculated in the following manner:

$$
\text { Percent swelling }\left(P_{S}\right)=\frac{W_{f}-W_{i}}{W_{i}} \times 100
$$

Moisture absorbance studies onto different natural fibers were carried-out at various humidity levels (20-100). Prior to moisture absorbance study the grafted and raw 
samples of Saccaharum ciliare fibres were dried at $50{ }^{\circ} \mathrm{C}$ in the oven till a constant weight was obtained. Moisture absorbance percentage was found out by placing the known weight $W_{i}$ of dried grafted and raw fibers in a humidity chamber (Swastika make) which was set to a particular humidity level for definite time interval and then the final weights $W_{f}$ of the samples exposed at a particular relative humidity $(\mathrm{RH})$ were taken. Same procedure was repeated at different humidities ranging from 20 to $100 \%$. The percent moisture absorbance was calculated from the increase in initial weight in the following manner.

$$
\% \text { Moisture absorbance }\left(\% M_{a b s}\right)=\frac{W_{f}-W_{i}}{W_{i}} \times 100
$$

Water uptake capacity of grafted and ungrafted fibers was studied by making the small wicks of diameter $5 \mathrm{~mm}$, which were dipped in the beaker containing $20 \mathrm{ml}$ of water. Rise of water through capillary action in each fiber wick was noted at different time intervals and percent water uptake $\left(P_{w}\right)$ was calculated as follows:

$$
P_{w}=\frac{T_{f}-D}{T_{f}}
$$

where $T_{f}$ is total fiber length and $D$ is the distance travelled by water in the fiber wicks.

To study the resistance of grafted as well as ungrafted fibers against chemicals, known weight of ungrafted and grafted fibers were put in the $100 \mathrm{ml}$ of $1 \mathrm{~N} \mathrm{HCl}$ and $1 \mathrm{~N} \mathrm{NaOH}$. The loss in weights of the grafted and ungrafted fibers was studied at different time intervals and \% chemical resistance $\left(P_{c r}\right)$ was calculated as follows:

$$
P_{c r}=\frac{T_{i}-T_{f}}{T_{i}} \times 100
$$

where $T_{i}$ is initial weight and $T_{f}$ is final weight after different time intervals.

\section{Evidence of grafting by characterization}

The infrared spectra of raw fiber and grafted fiber were recorded on Perkin-Elmer spectrometer. Scanning electron micrographs of raw fiber and its graft copolymer were recorded on Leo 435 VP.

X-ray diffraction analysis of samples of raw fiber and its graft copolymer were carried out on PW 1710 based machine.

The graft copolymerization of acrylonitrile onto raw Saccaharum cilliare fiber was confirmed by Fourier transform infrared, spectroscopic studies.

The IR spectra of raw Saccharum cilliare fiber showed a broad peak at $3370 \mathrm{~cm}^{-1}$ due to bonded $\mathrm{OH}$ groups and at $2922.4,1438$ and $1043 \mathrm{~cm}-1$ respectively due to $-\mathrm{CH} 2, \mathrm{C}-\mathrm{C}$, and $\mathrm{C}-\mathrm{O}$ stretching. In case of grafted fiber an additional peak at $2245 \mathrm{~cm}^{-1}$ was seen due to the presence of $\mathrm{C}=\mathrm{N}$ group of vinyl monomer (AN).

Scanning electron micrographs of raw fiber, fiber after removing lignin contents and grafted fibers of $S$. cilliare when compared showed a clear cut distinction in their surface 
morphology (Fig. 6). It has been observed that graft copolymerization of lignocellulosic fibers incorporates new functionalities into these fibres, and surface features of fibres are not clearly visible. Since these fibres exhibited micro pores on theirs surface, the new functionalities penetrated into the pores and formed a mechanically interlocked coating on their surface. This change in morphology causes changes in the properties of the raw fiber on graft copolymerization.
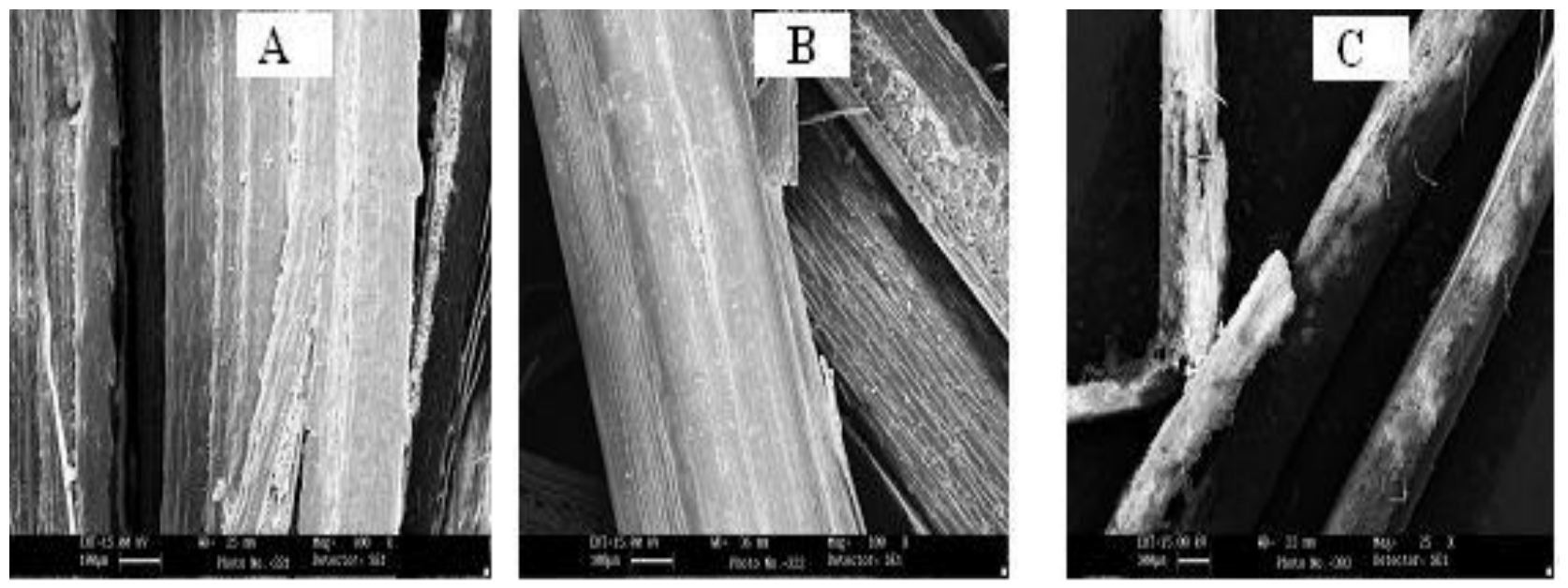

Fig. 6. SEM of raw, lignin free and grafted fiber (A, B, C).

Tab. 2. X-Ray Diffraction analysis of raw fiber, lignin free fiber and grafted fiber.

\begin{tabular}{|c|c|c|c|c|c|c|}
\hline \multicolumn{2}{|l|}{$2 \theta$} & \multicolumn{2}{|l|}{14.860} & \multicolumn{3}{|l|}{23.195} \\
\hline $\begin{array}{l}\text { Sr. } \\
\text { No. }\end{array}$ & $\begin{array}{l}\text { Sample } \\
\text { code } \\
\left(p_{g}\right)\end{array}$ & d $\dot{a}_{1}[A]^{0}$ & I [\%] & $\mathrm{d} \dot{\alpha}_{1}[\mathrm{~A}]^{0}$ & I [\%] & Der \\
\hline 1. & $F_{\text {raw }}$ & 5.9575 & 36.8 & 3.8374 & 98.5 & 67.5 \\
\hline 2. & $\mathrm{~F}_{\text {lig }}$ & 5.9868 & 16.2 & 3.8770 & 100.0 & 64.8 \\
\hline 3. & Cotton & 5.9568 & 37.6 & 3.8317 & 100.0 & 67.6 \\
\hline 4. & $F_{g}(19.3 \%)$ & 5.9090 & 38.4 & 3.9320 & 100.0 & 61.06 \\
\hline 5. & $F_{g}(15 \%)$ & 6.0131 & 16.0 & 3.9338 & 100.0 & 63.96 \\
\hline 6. & $F_{g}(15.4 \%)$ & 5.9093 & 40.4 & 3.8563 & 100.0 & 63.63 \\
\hline 7. & $F_{g}(17.8 \%)$ & 5.9293 & 37.6 & 3.9115 & 100.0 & 63.43 \\
\hline 8. & $F_{g}(25.5 \%)$ & 6.0070 & 37.1 & 3.9286 & 100.0 & 55.57 \\
\hline 9. & $F_{g}(69 \%)$ & 5.1948 & 74.7 & 3.8820 & 100.0 & 55.19 \\
\hline
\end{tabular}

where, $F_{\text {raw }}=$ raw fiber, $F_{\text {lig }}=$ lignin free fiber, $F_{g}=$ grafted fiber, $d=d$ spacing, $I=$ relative intensity, $D_{c r}=$ degree of crystallinity.

\section{References}

[1] Singha, A.S.; Thakur, V. K. Polymer Composites 2009, in Press. 
[2] Schilling, C.H.; Tomasik, P.; Karpovich, D.S.; Hart, B.; Shepardson, S.; Garcha, J.; Boettcher, P. T. J. Polym. Environ. 2005, 13, 77.

[3] Schilling, C.H.; Tomasik, P.; Karpovich, D. S.; Hart, B.; Shepardson, S.; Garcha, J.; Boettcher, P. T. J. Polym. Environ. 2004, 12, 257.

[4] Singha, A. S.; Thakur, V. K. Bulletin of Material Science 2008, 31, 5, 791.

[5] Singha, A.S.; Thakur, V.K. Iranian Polymer Journal 2008, 17, 7: 541.

[6] Singha, A.S.; Thakur, V. K. BioResources 2008, 3/4, 1173.

[7] Rahman, M. M.; Mallik, A. K.; Khan, M. A. Journal of Applied Polymer Science 2007, 105/5: 3077.

[8] Singha, A.S.; Thakur, V.K. Journal of Reinforced Plastics and Composites 2008, In Press.

[9] Singha, A.S.; Thakur, V. K. Inter. J. Plastic Tech. 2007, 11, 835.

[10] Singha, A.S.; Thakur, V.K. International Journal of Polymeric Materials 2008, 57/12, 1059.

[11] Schilling, C.H.; Tomasik, P.; Karpovich, D. S.; Hart, B.; Shepardson, S.; Garcha, J.; Boettcher P. T. J. Polym. Environ. 2005, 13, 57.

[12] Fan, G.; Zhao, J.; Yuan, H.; Guo, Z.; Wang, J.; Liang, G. Journal of Applied Polymer Science 2006, 102/1, 674.

[13] Rozman, H. D.; Faiza, M. A.; Kumar, R. N. Polymer-Plastics Technology and Engineering 2008, 47/ 4, 358.

[14] Singha, A.S.; Thakur, V. K. Inter. J. Plastic Tech. 2008, 12: 913.

[15] Song, Y.S.; Youn, J. R. e-Polymers 2004, 80, 1.

[16 ] Zhou, T. H.; Ruan, W. H.; Wang, Y. L.; Mai, Y. L.; Rong, M. Z.; Zhang, M. Q. ePolymers 2007, 58, 1.

[17] Kannan, M.; Bhagawan, S.S.; Joseph, K.; Thomas, S. e-Polymers 2008, 133, 1.

[18] Tomasik, P.; Schilling, C.H. Adv. Carbohydr.Chem. Biochem. 2004, 59, 175.

[19] Misra, B.N.; Sharma, R.K.; Singha, A.S. J. Appl. Polym. Sci. 1982, 27, 1321.

[20] Margutti, S.; Vicini, S.; Prometí, N.; Coniod, D.C.G.; Pedemontea, E.; Segre, A.L. Polymer 2002, 43/6, 183.

[21] Guan, Y.; Xiao, H.; Sullivan, H.; Zheng, A. CarbohydratePolymers, 2007, 69: 688.

[22] Singha, A.S.; Anjali, S.; Misra, B.N. J. Polym. Mater. 2008, 25 /1, 91.

[23] Chauhan, G.S.; Bhatt, S.S.; Kaur, I.; Singha, A.S.; Kaith, B.S. Journal of Polymer Degradation and Stability 2000, 69, 261.

[24] Shanks, R. A.; Hodzic, A.; Ridderhof, D. Journal of Applied Polymer Science 2006, 101/6: 3620.

[25] Liu, Z-T.; Sun, C.; Liu, Z-W.; Lu, J. Journal of Applied Polymer Science, 2008, 109/5, 2888.

[26] Román- Aguirre, M.; Márquez- Lucero, A.; Zaragoza-Contreras, E. A. Carbohydrate Polymers, 2004, 55, 201.

[27] Sabaa, M.W.; Mokhtar, S. M. Polymer Testing, 2002, 21, 337.

[28] Benke, N.; Takács, E.; Wojnárovits, L.; Borsa, J. Radiation Physics and Chemistry, 2007, 76, 1355.

[29] Singha, A.S.; Anjali, S.; Thakur, V.K. International Journal of Polymer Analysis and Characterizations 2008, 13 (6), xx.

[30] Singha, A.S.; Anjali, S.; Thakur, V.K. Bulletin of Material Science. 2008, 31 /1, 07.

[31] Sabaa, M. W.; Mokhtar, S. M. Polymer Testing, 2002, 21, 337. 
[32] Bakar, A. A.; Nik Mat, N.S.; Isnin, M. K. Journal of Applied Polymer Science, 2008, 110/2, 847.

[33] Prachayawarakorn, J.; Boonsawat, K. Journal of Applied Polymer Science, 2007, 106/3, 1526.

[34] Khan, F.; Ahmad, S. R. Journal of Applied Polymer Science 2006, 101/5: 2898.

[35] Wang, W.Y.; Chen, L.; Yu, X. Journal of Applied Polymer Science 2006, 101/2, 833.

[36] Lindqvist, J.; Malmström, E. Journal of Applied Polymer Science 2006, 100 / 5, 4155.

[37] Peng, Q.; Xu, Q.; Sun, D.; Shao, Z. Journal of Applied Polymer Science 2006, 100 / 2, 1299.

[38] Segal, L.C.; Martin, A.E.; Conrad, C. M. Textile Res J 1959, 29, 786. 